\title{
Optimal Policy for Deteriorating Items Ramp Type Demand with Shelf Life
}

\author{
KaiWayne Chuang \\ Department of Business Administration, Nanhua \\ University, Chiayi County, Taiwan. \\ e-mail: kwchuang@mail.nhu.edu.tw
}

\author{
ChienNan Lin \\ Department of Business Administration, Nanhua \\ University, Chiayi County, Taiwan. \\ e-mail: x4pili@yahoo.com.tw
}

\author{
ChunHsiung Lan \\ Department of Business Administration, Nanhua University, Chiayi County, \\ Taiwan. \\ e-mail:074003@mail.hwc.edu.tw
}

\begin{abstract}
In this article, we have studied the inventory and pricing strategies for deteriorating items with ramp type demand and shelf life. In practice, there are many commodity such as food, medication exist the shelf life expiration date. Therefore the shelf life expiration date has become an important research topic in inventory management. The objective is to find the optimal inventory maximizing the net present value of total profit over the infinite horizon. We will discuss two cases. We assume that the inventory objective is to minimize the total cost per unit time of the system.
\end{abstract}

Keywords- ramp type demand; deteriorating items; backlogging; shelf life.

\section{INTRODUCTION}

The effect of deterioration is very important in inventory management. In order to avoid the loss due to damage or expiration, it is importance to develop a proper inventory strategy. Most of the literature assumes that a constant proportion of items will deteriorate per time-unit while they are in storage. Ghare and Schrader established a model for an exponentially decaying inventory [1]. Covert and Philip used a variable deterioration rate of two-parameter Weibull distribution to formulate the model with the assumption of a constant demand rate without shortages [2]. Shah and Jaiswal presented an order-level inventory model for deteriorating items with a constant rate of deterioration [3]. Aggarwal developed a note on an order-level model for systems with a constant rate of deterioration [4]. Other researchers, such as Skouri and Papachristos discussed optimal stopping and restarting production times for an EOQ (Economic Order Quantity) model with deteriorating items and timedependent partial backlogging [5]. Jaggi, Aggarwal, and Goel studied optimal order policy for deteriorating items with inflation induced demand [6]. Teng, Ouyang, and Chen studied a comparison between two pricing and lotsizing models with partial backlogging and deteriorated items [7].
In reality, the demand for physical goods may be timedependent, stock-dependent and price-dependent. Dave and Patel studied the inventory model for deteriorating items with time-varying demand [8]. Hill presented the inventory models for increasing demand followed by a constant demand [9]. Mandal and Pal extended the inventory model with ramp type demand to deterioration items, also allowing shortages [10]. Manna and Chaudhuri studied the EOQ model with ramp type demand rate, time dependent deterioration rate, unit production cost and shortages [11]. Other researchers, there are many literatures that propose and evaluate the algorithms [12], [13], [14], [15], [16], [17], [18].

This study proposes a single-supplier, single-retailer optimal inventory for deteriorating items with ramp type demand and shelf life. Shelf life is the recommendation of time that products can be stored, during which the defined quality of a specified proportion of the goods remains acceptable under expected conditions of distribution, storage and display. Most shelf life dates are used as guidelines based on normal and expected handling and exposure to temperature. In practice, there are many commodities such as food, medication, therefore; the existence of shelf life expiration date has become an important research topic in inventory management. It is important to control and maintain the inventories of deteriorating items for the modern corporation. Besides, expressions for an inventory system's total cost are derived for the two cases described below. Sensitivity analysis of the optimal solution with respect to major parameters is carried out. Finally, a numerical example is presented to demonstrate the developed model and the solution procedure. The results can help managers determine the optimal total cost.

\section{NOTATIONS AND ASSUMPTIONS}

The mathematical model in this paper is developed on the basis of the following notations and assumptions.

A. Notations

$C_{1} \quad$ setup cost per setup. 
$C_{2} \quad$ unit holding cost per unit time.

$C_{3} \quad$ unit deteriorating cost per unit time.

$C_{4} \quad$ unit product expires lost cost.

$C_{5} \quad$ unit cost of lost sales.

$t_{1} \quad$ point of time when inventory level is maximum.

$t_{2} \quad$ point of time when all inventory is consumed.

$t_{1}+f \quad$ point of time when the shelf life expiration date.

$t_{3} \quad$ the production restarting time. (i.e., Model 2).

$t_{4}$. inventory cycle time (i.e., Model 2).

$I(t) \quad$ on-hand inventory at time $t$ over $\left[0, t_{4}\right]$.

Imax. the maximum inventory level.

$O C$ ordering cost per cycle.

$H C$ unit total holding cost per cycle.

$D C \quad$ unit deteriorating cost per cycle.

$E C \quad$ cost of lost product.

$S C \quad$ cost of lost sales per cycle.

$T C_{1} \quad$ total cost for a production cycle. (i.e., Model $1)$.

$T C_{2} \quad$ total cost for a production cycle. (i.e., Model

2).

$T V C_{1} \quad$ total average cost. (i.e., Model 1).

$T V C_{2}$ total average cost f. (i.e., Model 2).

\section{B. Assumptions}

In addition, the following assumptions are used throughout this paper.

1) A single item is considered and infinite planning horizon.

2) There is a single-supplier and a single-retailer for a single product in this model.

3) There is no replacement or repair for over the intended shelf life expiration date.

4) The initial and final inventory levels are both zero.

5) Demand rate $R=D(t)$ is assumed to be a ramp type function of time, where is the function defined as follows:

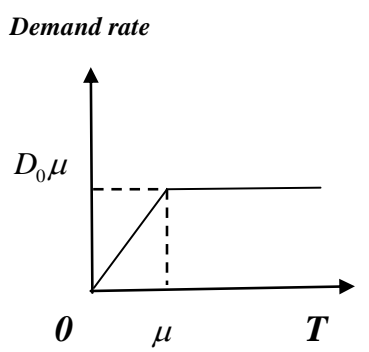

Figure 1. The ramp type demand rate

$$
\boldsymbol{D}(\boldsymbol{t})= \begin{cases}D_{0} t & \boldsymbol{t} \leq \mu, \\ D_{0} \mu & \mu \leq \boldsymbol{t} \leq T,\end{cases}
$$

6) $\quad P(t)=\beta D(t)$ is the production rate where $\beta(1<\beta$ $<2)$ is a constant.

7) Shortages are allowed to occur.

\section{MATHEMATICAL MODEL AND SOLUTION}

In this section, we will discuss two models: Model 1 is without shortage. The Model 2 is with shortage. Here the ramp type demand of an item is dependent on the relative size of $\mu$.

\section{A. Model 1. Model Without Shortage.}

In this model 1 , the production starts with zero stock level at time $t=0$ and the production stops at time $t_{1}$. Due to the combined effects of demand of items, the inventory level gradually diminishes during the period $\left[t_{1} ; t_{2}\right]$, product expires at time $t_{1}+f$, backlogging during the period $\left[t_{1}+f ; t_{2}\right]$ and ultimately falls to zero at time $t=t_{2}$.

The whole process is repeated and the behavior of the inventory system is depicted in "Fig.2".. The inventory cycle here has the following four phases:

Inventory level

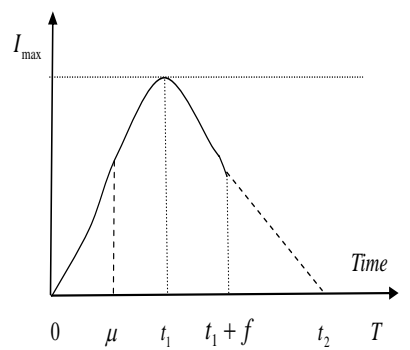

Figure 2. The inventory model without shortage.

Phase1. During the time interval $[0, \mu]$ the demand rate is $D_{0} t$, the production rate is $\beta D_{0} t$ and the deterioration rate is $\theta I_{1}(t)$ at time $t$. Therefore, the inventory level at time $t$, is governed by

$\frac{d I_{1}(t)}{d t}+\theta I_{1}(t)=(\beta-1) D_{0} t, 0 \leq t \leq \mu$

Phase2. During the time interval $\left[\mu, t_{1}\right]$, from assumptions (5) and Figure 1and "Fig.3", we know that the demand rate is $D_{0}$ the production rate is $\beta D_{0}$, and the deterioration rate is $\theta I_{2}(t)$ at time $t$. Therefore, the inventory level at time $t$, is governed by 


$$
\frac{d I_{2}(t)}{d t}+\theta I_{2} t=(\beta-1) D_{0} \mu, \mu \leq t \leq t_{1} .
$$

Phase3. In the time interval $\left[t_{1}, t_{1}+f\right]$, the system is affected by the combined the demand and deterioration. Hence, the inventory level at time $t$, is governed by

$\frac{d I_{3}(t)}{d t}+\theta I_{3} t=-D_{0} \mu, \quad t_{1} \leq t \leq t_{1}+f$.

Phase4. In the time interval $\left[t_{1}+f, t_{2}\right]$ the system is affected by the combined the demand and add the product expires and backlogging into the model. Hence, the inventory level at time $t$, is governed by

$\frac{d I_{4}(t)}{d t}=-D_{0} \mu, t_{1}+f \leq t \leq t_{2}$.

The solution to "(1)" is

$I_{1}(t)=\frac{e^{-t \theta}(\beta-1)\left(1-e^{t \theta}+e^{t \theta} t \theta\right) D_{0}}{\theta^{2}}, 0 \leq t \leq \mu$.

The solution to "(2)" is

$I_{2}(t)=\frac{e^{-t \theta}(\beta-1)\left(1+e^{t \theta} \theta \mu-e^{\mu \theta}\right) D_{0}}{\theta^{2}}, \mu \leq t \leq t_{1}$.

The solution to "(4)" is

$I_{4}(t)=\left(-t+t_{2}\right) D_{0} \mu, t_{1}+f \leq t \leq t_{2}$.

The solution to "(3)" is

$I_{3}(t)=-\frac{e^{-t \theta}\left(e^{t \theta}+e^{\left(f+t_{1}\right) \theta}\left(-1+\left(f+t_{1}-t_{2}\right) \theta\right)\right) D_{0} \mu}{\theta}$,

$t_{1} \leq t \leq t_{1}+f$.

we have the maximum inventory level is given by $I_{\max }=I_{3}\left(t_{1}\right)=I_{2}\left(t_{1}\right)$.

$\frac{e^{-t_{1} \theta}(\beta-1)\left(1+e^{\tau_{0}^{\theta} \theta} \theta \mu-e^{\mu \theta}\right) D_{0}}{\theta^{2}}$

$=-\frac{e^{-t_{1} \theta}\left(e^{t_{\theta} \theta}+e^{\left(f+t_{1}\right) \theta}\left(-1+\left(f+t_{1}-t_{2}\right) \theta\right)\right) D_{0} \mu}{\theta}$,

From "(9)", it is obvious that $t_{2}$ is a function of $t_{1}$. As a result, the problem here has only one decision variable $t_{1}$.

That is $t_{1}=\frac{1}{\theta}\left[1-e^{-f \theta} \beta-f \theta+t_{2} \theta+\operatorname{ProductLog}\left[\frac{e^{-1+e^{-\theta} \beta-h_{2} \theta}\left(-1+e^{\mu \theta}\right)(-1+\beta)}{\theta \mu}\right]\right.$.

The total cost per cycle consists of the following three elements:

(a) The setup cost is $O C=C_{1}$.

(b) The inventory holding cost is given by

$$
\begin{aligned}
H C_{1} & =C_{2}\left[\int_{0}^{\mu_{1}} I_{1}(t) d t+\int_{\mu_{1}}^{t_{1}} I_{2}(t) d t+\int_{t_{1}}^{t_{1}+f} I_{3}(t) d t\right] \\
& =\frac{1}{2 \theta^{3}}\left(e ^ { - t _ { 1 } \theta } \left(2+2\left(e^{\theta \mu}(-1+\beta)-2 \beta-2 e^{\theta\left(f+t_{1}\right.} \theta\left(-1+\left(f+t_{1}-t_{2}\right) \theta\right) \mu\right.\right.\right. \\
& \left.\left.-e^{t_{1} \theta} \theta \mu\left(2\left(\beta+t_{2} \theta-t_{1} \theta \beta\right)+(-1+\beta) \theta \mu\right)\right) C_{2} D_{0}\right) \cdot(11)
\end{aligned}
$$

(c) The cost of lost product over the intended shelf life per cycle is given by

$E C_{1}=C_{3} I_{3}\left(t_{1}+f\right)=-\left(f+t_{1}-t_{2}\right) \mu C_{3} D_{0}$,

(d) The inventory deteriorating cost is given by

$$
\begin{aligned}
D C_{1} & =C_{4}\left[\beta \int_{0}^{\mu} D_{0} t d t+\beta \int_{\mu}^{t_{1}} D_{0} \mu d t-\int_{0}^{\mu_{1}} D_{0} t d t-\int_{\mu}^{t_{1}} D_{0} \mu d t-\int_{t_{1}}^{t_{1}+f} D_{0} \mu d t\right] \\
& =-\frac{1}{2} \mu\left(2\left(f+t_{1}-t_{1} \beta\right)+(-1+\beta) \mu\right) C_{4} D_{0} .
\end{aligned}
$$

(e) The cost of lost sales per cycle is given by

$$
\begin{aligned}
S C_{1} & =C_{5} \int_{t_{t_{1}+f}+f}^{t_{2}} I_{4}\left(-t+t_{2}\right) \mu D_{0} d t \\
& =\frac{1}{2}\left(f+t_{1}-t_{2}\right)^{2} \mu C_{5} D_{0}
\end{aligned}
$$

Therefore, the total cost per unit time during time$\operatorname{span}\left[0, t_{2}\right]$ is given by

$$
\begin{aligned}
& T C_{1}\left(t_{1}, t_{2}\right)=O C+H C_{1}+E C_{1}+D C_{1}+S C_{1} \\
& T V C_{1}\left(t_{1}, t_{2}\right)=\frac{T C_{1}\left(t_{1}, t_{2}\right)}{t_{2}} .
\end{aligned}
$$

Hence, the total relevant cost per unit time is a function of one variable $t_{2}$ because of "(16)". The necessary condition for $T V C_{1}$ to be minimum is the optimal solution satisfies:

$\frac{d T V C_{1}}{d t_{2}} \mid\left(t_{2}\right)=0$.

provided they satisfy the sufficient conditions

$\frac{d^{2} T V C_{1}}{d t_{2}^{2}} \mid\left(t_{2}\right)>0$. 
Due to the fact that $t_{1}$ is a function of $t_{2}$, thus $T V C_{1}\left(t_{1} ; t_{2}\right)$ in "(16)" can be reduced as a function of $t_{2}$, we denoted it by $T V C_{1}\left(t_{2}\right)$, i.e., $T V C_{1}\left(t_{2}\right)=T V C_{1}\left(t_{1} ; t_{2}\right)$. Hence, the problem faced by the vendor in Model 1 is

Minimize $T V C_{1}\left(t_{2}\right)$ Subject to: $0 \leq t_{1} \leq t_{2}$.To minimize the total cost per unit time, taking the first derivative of $T V C_{1}\left(t_{2}\right)$ with respect to $t_{1}$, and setting the result to be zero, we obtain $\frac{d T V C_{1}\left(t_{2}\right)}{d t_{2}}=0$

Let $t_{1}{ }^{*}$ denoted the optimal value of $t_{2}$, then $t_{2}{ }^{*}$ must satisfy "(18)". Furthermore, we can see that the stationary point $t_{2}$ also satisfies the $\frac{d^{2} T V C_{1}}{d t_{2}{ }^{2}} \mid\left(t=t_{2}{ }^{*}\right)>0$

Consequently, we can obtain the value of $t_{2}{ }^{*}$ from "(17)", the numerical examples in section 4 below indicate so. Once the optimal solution $t_{2}{ }^{*}$ is obtained, the corresponding optimal value $t_{1}^{*}$ can be determined from "(9)".

\section{B. Model 2. Model with shortage}

In this model 2 , the behaviors of inventory system is depicted in "Fig.3".

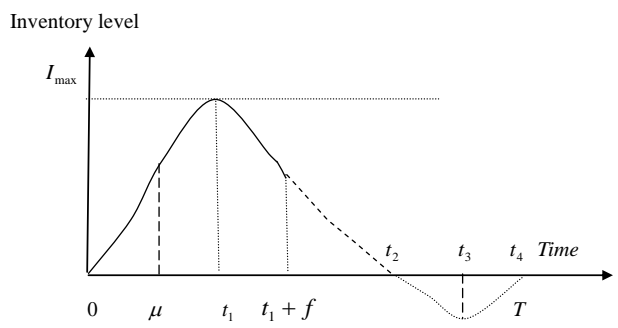

Figure 3. The inventory model with shortage.

The Phases 1, 2,3 and 4 are same as those in Model 1 .

Phase 5. During the shortage interval $\left[t_{2}, t_{3}\right]$, the demand at time $t$ is backlogged. Thus, the inventory level at time $t$ is governed by the following differential equation:

$$
\frac{d I_{5}(t)}{d t}=-D_{0} \mu, \quad t_{2} \leq t \leq t_{3}
$$

The solution of "(19)" is

$$
I_{5}(t)=\left(-t+t_{2}\right) D_{0} \mu, \quad t_{2} \leq t \leq t_{3} .
$$

Phase6. During the shortage interval $\left[t_{3}, t_{4}\right]$ the backorders level at time $t$, is governed by the following differential equation:

$$
\frac{d I_{6}(t)}{d t}=(\beta-1) D_{0} \mu, \quad t_{3} \leq t \leq t_{4}
$$

The solution to"(21)"is

$$
I_{6}(t)=\left(t-t_{4}\right)(\beta-1) D_{0} \mu, \quad t_{3} \leq t \leq t_{4}
$$

Given the condition $I_{5}\left(t_{3}\right)=I_{6}\left(t_{3}\right)$, we get

$$
\left.\left(-t_{3}+t_{2}\right) D_{0} \mu=\left(t_{3}-t_{4}\right)(\beta-1) D_{0} \mu\right) .
$$

From "(23)", it is obvious that $t_{2}$ is a function of $t_{3}$. As a result, the problem here has only one decision variable $t_{3}$.

$t_{3}=\frac{t_{2}-t_{4}+t_{4} \beta}{\beta}$,

The total cost per cycle of the system consists of the following five elements:

(a) The setup cost is $\boldsymbol{O C}=C_{1}$.

(b) The inventory holding cost is $H C_{2}=H C_{1}$.

(c) The inventory deteriorating cost is $D C_{2}=D C_{1}$.

(d) The cost of lost product over the intended shelf life is $E C_{2}=E C_{1}$.

(e) The cost of lost sales is $S C_{21}=S C_{1}$

(f)The cost of lost sales is given by

$$
\begin{aligned}
& S C_{22}=C_{5}\left[\int_{t_{2}}^{t_{3}}-I_{4}(t) d t+\int_{t_{3}}^{t_{4}}-I_{5}(t) d t\right] \\
& =\frac{1}{2}\left(\left(t_{2}-t_{4}\right)\left(t_{2}-2 t_{3}+t_{4}\right)+\left(t_{3}-t_{4}\right)^{2} \beta\right) C_{5} \mu D_{0}
\end{aligned}
$$

Consequently, the total cost per unit time during time$\operatorname{span}\left[0, t_{4}\right]$ is given by

$T C_{2}\left(t_{1}, t_{2}, t_{3}, t_{4}\right)=O C+H C_{2}+D C_{2}+E C_{2}+S C_{21}+S C_{22}$.

where

$$
T V C_{2}\left(t_{1}, t_{2}, t_{3}, t_{4}\right)=\frac{T C_{2}\left(t_{1}, t_{2}, t_{3}, t_{4}\right)}{t_{4}}
$$

From "(9)"and "(23)", we know that $t_{2}$ is a function of $t_{1}$ and $t_{4}$ is a function of $t_{2}$ and $t_{3}$ Consequently, the decision variables in Model 2 can be reduced from four dimensions $\left(t_{1}, t_{2}, t_{3}, t_{4}\right)$ to two dimensions $\left(t_{1}, t_{3}\right)$, i.e., the problem faced by the vendor in this model is 
Minimize: $T V C_{2}\left(t_{1} ; t_{3}\right)$

\section{Subject to: $0 \leq t_{1} \leq t_{2}, t_{2} \leq t_{3} \leq t_{4}$.}

Our objective is to find the optimal values of $t_{1}$ and $t_{3}$ such that $T V C_{2}\left(t_{1} ; t_{3}\right)$ has minimum. That is, in order to find the optimal values of $t_{1}$ and $t_{3}$, we have to solve the complex nonlinear equations $\frac{\partial T V C_{1}\left(t_{1}, t_{3}\right)}{\partial t_{1}}=0$ and $\frac{\partial T V C_{1}\left(t_{1}, t_{3}\right)}{\partial t_{3}}=0$.

We can obtain the optimal values $t_{1}{ }^{*}$ and $t_{3}{ }^{*}$. Once we obtain the optimal value $\left(t_{1}{ }^{*} ; t_{3}{ }^{*}\right)$, the optimal solution $\left(t_{2}{ }^{*} ; t_{4}{ }^{*}\right)$ is obtained from "(9)" and "(23)".

\section{NUMERICAL EXAMPLES AND SENSITIVITY ANALYSIS}

A. We let $C_{1}=\$ 1000$ per setup, $C_{2}=\$ 30 /$ unit, $C_{3}=\$ 50 /$ unit, $C_{4}=\$ 20 /$ unit, $C_{5}=\$ 10 /$ unit,$\mu=1$, $\mathrm{D} 0=3, \beta=1.3, \theta=0.03, f=0.25$,.in appropriate units. By using the subroutine FindRoot in commercial software Mathematica 5.2.

B. Example 1: For the model 1 with shortage,we obtain the optimal solutions for $t_{1}{ }^{*}, t_{2}{ }^{*}$ and $T V C_{1}{ }^{*}$ are given as $t_{1}{ }^{*}=8.69653, t_{2}{ }^{*}=10.8609$, and $T V C_{1}{ }^{*}=217.163$

C. Example 2: For the model 2 without shortage, we obtain the optimal solutions for $t_{1}{ }^{*} ; t_{2}{ }^{*} ; t_{3}{ }^{*} ; t_{4}{ }^{*}$ and $T V C_{2}{ }^{*}$ are given as $t_{1}{ }^{*}=3.01378, t_{2}{ }^{*}=3.73534$, $t_{3}{ }^{*}=7.25921, t_{4}{ }^{*}=19.0054$ and $T V C_{2}{ }^{*}=105.716$

\section{Sensitivity Analysis}

For studying the sensitivity analysis of the parameters on the proposed models, we changed (increasing or decreasing) the parameters by $25 \%$ and $50 \%$ and took one parameter at a time, kept the remaining parameters at their original values.

a) Example 1:

(1) The optimal total cost per unit time, $T V C_{1}{ }^{*}$ increases while $C_{1}, C_{2}, C_{3}, C_{4}, C_{5}, \mu, D_{0}$ and $\beta$ increase. But this trend is reversed for parameters $\theta$ and $f$.

(2) A larger value of $C_{1}$ indicates a larger setup cost per setup, while the optimal total average cost per unit time is getting larger.

(3) A larger value of $C_{2}$ indicates a larger unit holding cost per unit time; while the optimal total average cost per unit time is getting larger.

(4) A larger value of $C_{3}$ indicates a unit product expires lost cost per unit time, while the optimal total average cost per unit time is getting larger.

(5) A larger value of $C_{4}$ indicates a unit deteriorating cost per unit time, while the optimal total average cost per unit time is getting larger.

(6) A larger value of $C_{5}$ indicates a unit product lost cost per unit time, while the optimal total average cost per unit time is getting larger.

(7) A larger value of $\mu$ parameter, while the optimal total average cost per unit time is getting larger.

(8) a larger of $\theta$ deterioration rate, while the optimal total average cost per unit time is getting smaller.

(9) A larger value of $f$ parameters, while the optimal total average cost per unit time is getting larger.

(10) A larger value of $D_{0}$ parameters, while the optimal total average cost per unit time is getting larger.

(11) It is seen that the percentage change in the optimal total average cost per unit time is highly sensitive in parameters $C_{1}, C_{2}, \mu$ and $D_{0}$.

b) Example 2:

(1) The optimal total cost per unit time $T V C_{2}{ }^{*}$ increases while $C_{1}, C_{2}, C_{3}, C_{4}, C_{5}, \mu$, and $D_{0}$ increase. But this trend is reversed for parameters $\theta$ and $f$.

(2) A larger value of $C_{1}$ indicates a larger setup cost, while the total average cost per unit time is getting larger.

(3) A larger value of $C_{2}$ indicates a larger unit holding cost per unit time, while the total average cost per unit time is getting larger.

(4) A larger value of $C_{3}$ indicates a unit product expires lost cost per unit time, while the optimal total average cost per unit time is getting larger.

(5) A larger value of $C_{4}$ indicates a unit deteriorating cost per unit time, while the optimal total average cost per unit time is getting larger.

(6) A larger value of $C_{5}$ indicates a unit product lost cost per unit time, while the optimal total average cost per unit time is getting larger.

(7) A larger value of $\mu$ parameters, while the total average cost per unit time is getting larger.

(8) A larger value of $\theta$ parameters, while the optimal total average cost per unit time is getting smaller.

(9) A larger value of $f$ parameters, while the optimal total average cost per unit time is getting smaller. 
(10) A larger value of $D_{0}$ parameters, while the total average cost per unit time is getting larger.

(11) It is seen that the percentage change in the optimal total average cost per unit time is highly sensitive in parameters $C_{1}, C_{5}, \mu$ and $D_{0}$.

\section{CONCLUDING REMARKS}

This study proposes a single-supplier, single-retailer optimal inventory for deteriorating items with ramp type demand and shelf life. Shelf life is the recommendation of time that products can be stored, during which the defined quality of a specified proportion of the goods remains acceptable under expected conditions of distribution, storage and display. In practice, there are many commodities such as food, medication. Therefore the existence of shelf life expiration date has become an important research topic in inventory management.This paper presented a methodology and provided numerical results related to ramp type demand rate to find the optimal inventory policy. Two numerical examples are given to illustrate the solution procedure and sensitivity analysis has been shown.

\section{REFERENCES}

[1] Ghare, P.M. and Schrader, G.H, "A model for exponentially decaying inventory system," International Journal of Industrial Engineering, Vol.14, pp238-243, 1963.

[2] Covert, R. P., Philip, G. C, “An EOQ model for items with weibull distribution deterioration," AIIE Transactions, Vol. 5, 323-326, 1973.

[3] Shah, Y. K. and Jaiswal, M. C, "An order-level inventory model for a system with constant rate of deterioration," Opsearch, Vol.14, pp174-184, 1977.

[4] Aggarwal, S. P. (), "A note on an order-level model for a system with constant rate of deterioration," Opsearch, Vol. 15, pp.184187,1978 .

[5] Skouri K. and Papachristos, S, "Optimal stopping and restarting production times for an EOQ model with deteriorating items and time-dependent partial backlogging," International Journal of Production Economics, Vol. 81-82, pp525-531, 2003.

[6] Jaggi, C. K., Aggarwal, K. K. and Goel, S. K, “ Optimal order policy for deteriorating items with inflation induced demand,"
International Journal of Production Economics, Vol. 103, pp707$714,2006$.

[7] Teng, J.-T., Ouyang, L.Y. and Chen, L.H, "A comparison between two pricing and lot-sizing models with partial backlogging and deteriorated items," International Journal of Production Economics, Vol. 105, pp190-203, 2007.

[8] Dave, U. and Patel, L.K, “(T, Si) policy inventory model for deteriorating items with time proportional demand," Journal of the Operation Research Society, Vol. 32, pp137-142, 1981.

[9] Hill, R. M, “ Inventory model for increasing demand followed by level demand," Journal of the Operational Research Society, Vol. 46, pp1250-1259, 1995 .

[10] Mandal, B. and Pal, A. K, "Order level inventory system with ramp type demand rate for deteriorating items," Journal of Interdisciplinary Mathematics, Vol.1, pp49-66, 1998.

[11] Manna, S. K. and Chaudhuri, K. S, "An EOQ model with ramp type demand rate, time dependent deterioration rate, unit production cost and shortages," European Journal of Operational Research, Vol. 171, pp557-566, 2006.

[12] Chen, L. H., Ouyang, L.Y. and Teng, J.T, “ On an EOQ Model with Ramp Type Demand Rate and Time Dependent Deterioration Rate," International Journal of Information and Management Sciences, Vol. 17, 51-66, 2006.

[13] Panda, S., Senapati, S. and Basu, M, "Optimal replenishment policy for perishable seasonal products in a season with ramp-type time dependent demand," Computers \& Industrial Engineering, Vol. 54, 301-314, 2008.

[14] M. Cheng, B. Zhang and G. Wang, “ Optimal policy for deteriorating items with trapezoidal type demand and partial backlogging," Applied Mathematical Modelling, vol. 35, pp. 3552-3560, 2011.

[15] R. Uthayakumar and M. Rameswari, " An economic production quantity model for defective items with trapezoidal type demand rate," Journal of Optimization Theory and Applications, vol. 154, pp. 1055-1079, 2012.

[16] C.H Tsai, D.S. Zhu, Y.L. Lan, and D. L. Li, "A Study on the Using Behavior of Depot-Logistic Information System in Taiwan: An Integration of Satisfaction Theory and Technology Acceptance Theory," Journal of Multimedia, vol. 8, pp106-116, 2013.

[17] Y. Sun and Q. Wang, "Demand analysis of water resources based on pulse process of complex system," Journal of Networks, vol. 8, 2013, pp. 910-916.

[18] P. Yang, J. Qin and W. Zhou, " Multi-commodity flow and multiperiod equilibrium model of supply chain network with postponement strategy," Journal of Networks, vol. 8, pp. 389-396, 2013. 